\title{
USO DE ENZIMAS PARA ESTABILIZAÇÃO DE SOLOS
}

\author{
USE OF ENZYMES FOR SOIL STABILISATION
}

lasminy Souza Alencar Edson Andrade Ferreira ${ }^{2}$ Elison de Souza Sevalho ${ }^{3}$

\section{RESUMO}

A estabilização tem função de modificar as propriedades naturais do solo, estas condições podem ocorrer por diversas técnicas, dos quais se destacam o uso de a ditivos químicos, como o uso de bioenzimas, biocatalizadores de partículas de solos desenvolvidas para aperfeiçoar as propriedades de engenharia geotécnica do solo. Desta forma, este estudo possui relevância, devido, as pesquisas relacionadas a temática, serem bastantes escassos na literatura científica. Nesta perspectiva, este artigo tem como objetivo fazer uma revisão bibliográfica descrevendo a utilização de bioenzimas com aplicação na estabilização de solos. Sendo assim, o uso dos aditivos enzimáticos na engenharia rodoviária como um produto alternativo bastante interessante nas condições de economia e sustentabilidade, visto que são ecológicos e não agridem o meio ambiente. Portanto, conhecer o potencial desses aditivos ou propor novas metodologias de ensaio capaz de avaliar a influência desses agentes estabilizadores em todos as categorias de solos têm sido o maior desafio dos pesquisadores nas últimas décadas.

Palavras-chave: Biocatalizadores. Aditivo enzimático. Estabilização de solos.

\section{ABSTRACT}

Stabilization has the function of modifying the natural properties of the soil. These conditions can occur through several techniques, such as the use of chemical additives, such as the use of bioenzymes, biocatalysts of soil particles developed to improve the geotechnical engineering properties of the soil. Thus, this study has relevance due to the fact that research related to the theme is scarce in the scientific literature. In this perspective, this article aims to make a literature review describing the use of bioenzymes with application in soil stabilization. Thus, the use of enzymatic additives in civil construction as a very interesting alternative product in the conditions of economy and sustainability, since they are ecological and do

1 Graduanda em Engenharia Civil pelo Centro Universitário do Norte (UNINORTE). E-mail: iasminyalencar@gmail.com

2 Mestre em Engenharia de Produção pela Universidade Federal do Amazonas (UFAM). Docente do Centro Universitário do Norte (UNINORTE). E-mail: edsonandradef@gmail.com

3 Doutorando em Biodiversidade e Biotecnologia pela Universidade do Estado do Amazonas (UEA).

E-mail: elisonsevalho@hotmail.com 
not harm the environment. Therefore, knowing the potential of these additives or proposing new test methodologies capable of evaluating the influence of these stabilizing agents in all soil categories has been the greatest challenge of researchers in recent decades.

Keywords: Biocatalysts; Enzymatic additive; Biotechnology; Soil stabilization; Civil construction.

\section{INTRODUÇÃO}

Dentro da engenharia geotécnica, uma tendência industrial na construção rodoviária é a busca por novas tecnologias construtivas que atendam características adaptadas a realidade brasileira, apresentando vantagens técnicas, econômicas e que tange a conservação sustentável. O projeto de pavimentação é de grande importância na análise de requisitos técnicos, onde descreve as propriedades e características mecânicas do solo que se encontra disposto no local de execução. Deste modo, existe com certa frequência o uso de solos que não apresentam qualidades naturais para suportar as cargas impostas ao pavimento rodoviário (RIBEIRO et al., 2018).

O projeto de pavimentação é de grande importância na análise de requisitos técnicos, onde descreve as propriedades e características mecânicas do solo que se encontra disposto no local de execução. Deste modo, existe com certa frequência o uso de solos que não apresentam qualidades naturais para suportar as cargas impostas ao pavimento rodoviário (FIROOZI et al., 2017; RIBEIRO et al., 2018).

Segundo os autores Eujine et al. (2017b), o solo, corresponde um dos recursos naturais mais abundante e barato, porém, para aplicação como material em camadas de pavimentos ou para suporte de estruturas de engenharia, precisa-se ser bem estudado, devido sua condição natural, nem sempre apresentar condições técnicas suficiente. Desta maneira, torna-se indispensável o estudo de métodos e técnicas de estabilização de solos para o progresso que atenda às solicitações de segurança e economia (DOS SANTOS, 2018).

O método de estabilização possui o objetivo de modificar as características e propriedades naturais do solo, estas condições podem ocorrer por diversas e distintas técnicas, dos quais se destacam os processos químicos. A estabilização química, conhecido também como aditivo químico consiste na adição de um determinado composto orgânico, como a bioenzimas ao solo, dessarte a acarretar transformações que induzem as características de deformabilidade, resistência mecânica e permeabilidade, alcançando o objetivo de estabilizá-lo (FIROOZI et al., 2017; GANAPATHY et al., 2017).

De acordo com Eujine et al. (2017b); Sahoo, Sridevi (2018) as bioenzimas são biocatalizadores de partículas de solos, apresentando-se como substâncias 
orgânicas superconcentradas, desenvolvidas para aperfeiçoar as propriedades de engenharia geotécnica, melhorando a cimentação entre os elementos, densidade e resistência a umidade, resultando numa capacidade de sua massa e maior estabilidade, encontrando aplicação na pavimentação rodoviária.

Desta forma, este estudo possui relevância no interesse em realizar pesquisas abordando a estabilização de solos com aditivos enzimáticos, pois, tratase de é um tema pelos menos no Brasil, pouco pesquisado, aliás, bem escassos, não frequentemente publicáveis, mesmo esses compostos químicos aperfeiçoe as características mecânicas dos materiais, sendo um tratamento de baixo custo e ambientalmente adequado, de modo a viabilizar projetos de pavimentos rodoviários. Nesta perspectiva, este estudo objetivou descrever a utilização das bioenzimas com aplicação na estabilização de solos, buscando seu melhoramento técnico funcional.

\section{METODOLOGIA}

Trata-se de uma pesquisa realizada por meio de uma revisão crítica da literatura, buscando reunir e sintetizar os resultados encontrados em trabalhos científicos que analisaram exclusivamente o uso de bioenzimas para estabilização de solos, contribuindo para o conhecimento da temática. Realizou-se o levantamento dos referenciais bibliográficos entre os meses de maio a outubro de 2018 nas bases de dados de ScienceDirect; ASCE Library; Engineering Village; Web of Science e Avery. Optou-se por utilizar somente artigos científicos, utilizando os seguintes descritores com operadores booleanos em inglês: "bio-enzyme, stabilization" OR ("bio-enzyme"[All Fields] AND "stabilization"[All Fields]) OR "Soil, Stabilization, Using, Enzymatic" AND brazil OR "engineering" [All Fields] OR "paving" OR "application of enzymes" OR "Terrazyme".

\section{REVISÃO BIBLIOGRÁFICA}

\section{PRINCIPAIS CARACTERÍSTICAS DA ESTABILIZAÇÃO DE SOLOS}

Dentre os materiais mais usados na construção civil, encontra-se o solo, um recurso natural abundante da crosta terrestre. Tratando-se de terraplenagem e pavimentação, o solo faz parte do subleito, englobando a base até o revestimento primário. Com certa frequência, há solos que não apresentam, total ou parcialmente os requisitos técnicos mínimos impostos ao pavimento, desta forma o engenheiro precisa adotar medidas, tais como a estabilização do solo existente (EUJINE et al., 2017b). 
Firoozi et al. (2017) descrevem a estabilização como técnica a acrescentar resistência de um determinado material, para melhorar seu comportamento do ponto de vista da engenharia, aos esforços diários de tráfego e adversidades ocasionados pela natureza. Esse procedimento é comumente aceita como método eficaz para a reparação da baixa qualidade do solo para que possam ser utilizados em pavimentações rodoviárias. A estabilização dos solos pode ocorrer através de diferentes técnicas, dos quais se destaca por método mecânico, físicos e químicos, sendo indicada e adaptadas de acordo com a finalidade da obra, pelo custo e em particular, pelas características dos materiais e propriedades do solo que devem ser corrigidas (MALKO et al., 2015).

O método de estabilização mecânica, refere-se ao processo de compactação de um determinado solo, com objetivo de diminuir a porosidade ocasionada pelas sucessivas cargas. Essa densificação gerada é usada em todas as camadas do pavimento, sendo realizada através de um equipamento mecânico, geralmente um rolo compactador ou algumas situações podem ser empregados o uso de valetas, ou soquetes manuais (LAKHANPAL, A.; CHOPRA, 2018). A correção granulométrica é outro método de estabilização mecânica, estimulada por homogeneização através de diferentes tipos solos e posterior compactação, resultando em um novo material com porcentagem limitada de partículas finas e bem graduado, para alcançar determinado desígnio abrangente na engenharia rodoviária (HABIBA AFRIN, 2017).

Ainda sobre a temática, Phummiphan et al. (2018) descrevem a estabilização física do solo, como método usualmente empregado na pavimentação, podendo ser classificada como parte da estabilização mecânica, consistindo em um método empregado na alteração das propriedades do solo, atuando principalmente na textura que visa a melhora das características estruturais e de drenagem dos solos, podendo ocorrer através de técnicas que envolvem os processos térmicos de secagem e eletro-osmose.

O tratamento térmico de secagem, consiste em técnica de aquecimento capaz de introduzir no solo uma mistura de ar quente e combustível, através da queima de combustíveis ou por processos elétricos. Entretanto, outro processo térmico, ocorre por resfriamento, ocorrendo estabilização pelo congelamento artificial da água intersticial, ocasionando um material rígido com elevada resistência (PHUMMIPHAN et al., 2018).

Para Habiba Afrin (2017), o processo eletro-osmose, constitui-se em posicionar dois eletrodos, para que passe uma corrente elétrica numa massa do solo, promovendo a migração da água entre o eletrodo positivo para o negativo, desta forma, ocasionando a diminuição da água no solo e consequentemente permitindo sua consolidação. 


\section{MÉTODO QUÍMICO PARA ESTABILIZAÇÃO DE SOLOS}

O método químico para estabilização dos solos teve grande impacto durante e após a Segunda Grande Guerra mundial, visando sanar os problemas militares de tráfego emergencial e temporário, assim como atuar nos programas de progresso e expansão rodoviárias, pois, na época a utilização de estabilização com cal e cimento era inviável devido às grandes quantidades demandadas desses materiais. No Brasil, o método químico surgiu em meados dos anos 60, desenvolvendo-se nos anos 70, quando também houve a liberação da importação de vários aditivos de origem sul-Africana, Argentina, Suíça, Uruguaia, Americana (FIROOZl et al., 2017; DOS SANTOS, 2018).

De acordo com Machado et al. (2017), o uso do método químico consiste em usar aditivos químicos visando as interações entre as partículas de solo e as moléculas de água, ocasionando a permeabilidade, resistência mecânica e deformabilidade do solo. Segundo Mukesh et al. (2018) o princípio do uso de aditivo químico na estabilização é criar moléculas capazes de unir as partículas e assim formar um compósito solo-aditivo bem resistente.

Dentre as reações químicas capazes de controlar a propriedades tensãodeformação, estabilidade volumétrica e resistência do solo, pode-se destacar: troca catiônica, reações cimentícias e pozolânicas. Machado et al. (2017) descreve quatro técnicas de estabilização química do solo como o solo-cimento; por uso de aglutinantes; por material betuminoso; por adição de materiais higroscópicos, tais como os cloretos de cálcio e sódio, resultando na retenção da umidade dos solos.

Neste contexto, um aditivo químico ideal deve ser inicialmente hidrófobo, deve ser resistente à oxidação e ao ataque de micro-organismos; possuir afinidade às superfícies internas e externas do argilomineral do que a água, deve ser aplicável como um líquido de baixa viscosidade e formar cimento sólido num tempo razoável e controlável e deve ter valores módicos (RAHGOZAR et al., 2018).

Em estudo realizado pelos autores Matthew e Paul (2018), utilizaramse métodos convencionais de estabilização, empregando cal e cimento em comparativo com uma mistura de aditivos químicos em um solo com cerca de $44 \%$ de silte e argila, e notou-se significante aumento do índice de suporte Califórnia e diminuição do índice de plasticidade, o que os caracteriza como material tanto para base ou sub-base de pavimento. Mas devido aos custos comparativos, o uso da cal se mostrou mais viável economicamente.

\section{FUNDAMENTOS DO EMPREGO DE ADITIVOS QUÍMICOS ORGÂNICOS NA ESTABILIZAÇÃO DE SOLOS}

Os primeiros aditivos orgânicos foram desenvolvidos a base de lignosulfatos, com a finalidade de evitar a formação de lama e poeira. Todavia, com as 
pesquisas avançadas descobriram compostos químicos orgânicos com utilidade na pavimentação, tais como: resinas aglutinantes, cátions orgânicos de amônia gordurosa, ácido sulfônico aromático de grande poder de aglutinação, resina emulsionada e enzimas isoladas da saliva (cupim) (KUSHWAHA et al., 2018).

Os produtos utilizados como aditivos orgânicos, apresentam-se nos mais variados "standards", operando em função da natureza distinta de seus componentes e os dos solos, resultando em diferentes categorias de estabilização. Várias teorias são propostas para os fenômenos que ocorrem nas interações entre esses materiais orgânicos e os minerais; é o estudo das interações organominerais, que geram os compostos organominerais (RAJORIA; KAUR, 2014).

Segundo Manu e Mahendra (2018), acreditam-se que os aditivos orgânicos ideais devem apresentar concordância em relação as seguintes características: apresentar solubilidade em água quando adicionados ao solo e durante o período de misturação e compactação; devem ser insolúveis em água após completada as reações de estabilização; de alguma maneira deve ligar diretamente as partículas entre si, ao invés de funcionar como se o mineral fosse um filler inerte; devem ser resistentes à decomposição bioquímica; devem ser baratos e/ou capazes de ser usados em pequenas quantidades, o suficiente para serem utilizados em grande escala (SODHI; OCEAN, 2018).

Vários standards de aditivos orgânicos estabilizantes de solos são produtos desenvolvidos a partir de macromoléculas, estas muitas vezes denominadas de macroíons, (macrocátions e macroânions). As macromoléculas poliméricas podem ser lineares, ramificadas, flexíveis de modo a estabelecer vários pontos de contato com as superfícies argilosas. Objetivando competir com íons e moléculas de água na preferência pelos pontos de adsorção das superfícies argilominerais, os quais são governados principalmente pela carga exibida (RAFIQUE et al., 2016; SAHOO, SRIDEVI, 2018).

Os aditivos orgânicos são divididos em categoria de acordo com os componentes catiônicos, aniônicos e não-iônicos. Facilmente condensam e se associam, ou submetem-se as reações inversas. Podem ser acrescentados ao solo na forma de pó, como líquidos, soluções ou emulsões, de maneira a garantir sua distribuição homogênea e proporcionar um contato eficiente aditivo-partículas do solo (GANAPATHY et al., 2018).

Todavia, de acordo com Eujine et al. (2018a), pelo fato dos aditivos orgânicos para estabilização, ainda não estarem consagrados no meio profissional e de pesquisas cientificas, não existem relatos relacionados à natureza dos aditivos identificando as seguintes classes e sub-classes.

Os aditivos orgânicos podem ser aplicados para a melhoria de materiais a serem utilizados em camadas de pavimento; construção de bases de pátios de estacionamento; camadas minimizadoras de ruídos e vibrações; na reciclagem de pavimentos; no auxílio para a melhora das condições de compactação de solos 
e em outras áreas como, por exemplo, controle de erosão, injeção de reforço de fundações, fabricação de materiais para alvenaria, construção de lagos artificiais (MACHADO et al., 2017). Existem relatos de projetos experimentais desenvolvidos com a utilização de bioenzimas nos estados do Rio Grande do Sul, Paraná e Ceará com aditivo estabilizante em diversos tipos de materiais terrosos em diferentes aplicações rodoviárias (DOS SANTOS, 2018).

\section{FUNDAMENTOS DA ESTABILIZAÇÃO DOS SOLOS USANDO BIOENZIMAS}

A utilização de bioenzimas como agente orgânica estabilizante de solo vem sendo pesquisada hodiernamente, devido demonstrarem características bastante interessantes. Uma bioenzima, assim denominada, por ser biocatalizadora atuante em sistemas vivos (animais, plantas e micro-organismos) acelerando as reações bioquímicas (SHAKA; SHAKA, 2016). Desta forma, uma bioenzima é empregada como biocatalizadora de partículas de solos, formulada para aperfeiçoar as propriedades de solo: aumentar a densidade, cimentação entre suas partículas e resistência à umidade, resultando maior estabilidade e capacidade de massa para suportar maiores cargas (BABY et al., 2016; CARMONA et al., 2017).

As bioenzimas tem ação diretamente ligada à fração silte e fração argila dos solos, pois, essas frações são as mais abundantes do material alvo desse tipo de técnica de estabilização. O aditivo à base de bioenzimas, necessita de alta concentração de argila, devido os finos possuírem húmus, uma fonte de substratos para catalise das enzimas (MALKO et al., 2015; RAMAN et al., 2018).

As ações dos aditivos estabilizantes enzimáticos produzidos possuem a finalidade de realizar catalise, resultando na cimentação e impermeabilização de partículas de solos, em substituição aos produtos convencionais tais como cal e cimento (MATTHEW, PAUL, 2018). Segundo Rajoria, Kaur (2018), quando as bioenzimas são homogeneizadas no solo com água, realizam reações catalise, gerando produtos que se entrosam nas partículas minerais, amalgamado e unindo todos os componentes do solo. As ações secundárias compreendem a lubrificação das constituintes químicos do solo, assim como diminui a tensão superficial da água, resultando em maiores densidades na compactação, consequentemente, oferecendo maior resistência a cargas (AGARWAL, KAUR, 2014; RAFIQUE et al., 2016), como pode ser visualizado na Figura 1. 
Figura 1: Reação catalítica do aditivo enzimático EMC squared ao solo.

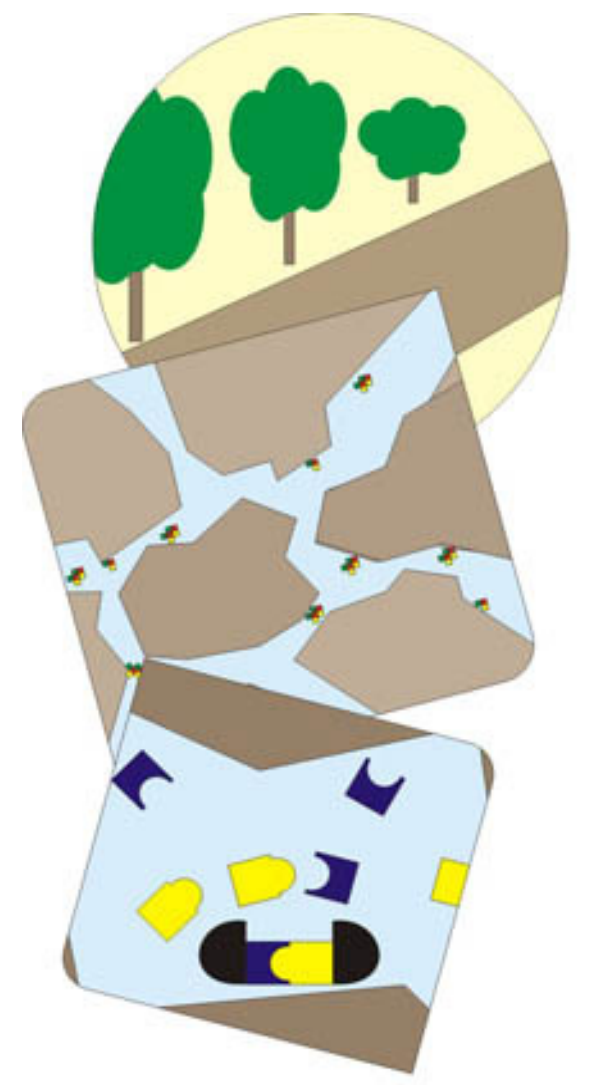

Solo normal

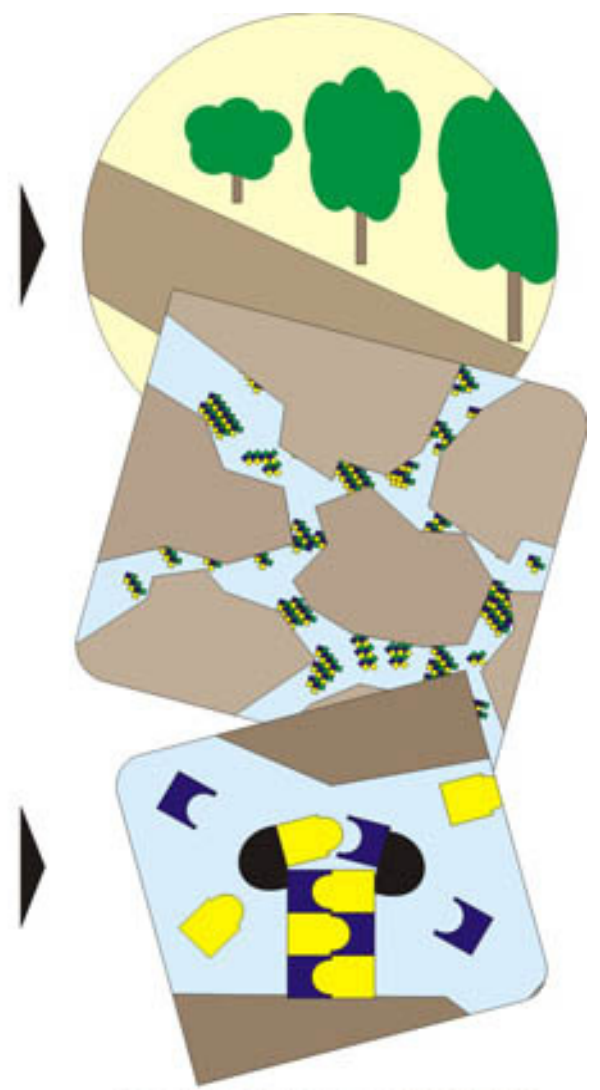

SOlO com EMG2

Fonte: http://www.baseforte.net/producto.html

Compreender o princípio do processo de estabilização enzimática do solo, abrange um embasamento multidisciplinar de profissões e ocupações especializadas, que englobam os engenheiros civis, biotecnologistas, geólogos, agrônomos, ambientalistas e os zoólogos. Paulatinamente, os profissionais corroboram com um resultado ou informação que enriquece o entendimento do processo de estabilização enzimática, estudo dos complexos orgâno-argilominerais, em especial o enzimo-argilomineral (MALKO et al., 2015; SAHOO, SRIDEVI, 2018).

\section{APLICAÇÃO DAS BIOENZIMAS NA ESTABILIZAÇÃO DOS SOLOS}

As pesquisas com aditivos enzimáticos como agentes estabilizantes apresentam um porvindouro promissor, devido sua fabricação não agredir o meio ambiente, ao contrário dos aditivos químicos inorgânicos convencionais como a cal, pozolanas e o cimento (THOMAS et al., 2018). Ademais, as fabricações dos aditivos enzimáticos são simples, pois, utiliza matéria-prima renovável podendo ser fabricada através da técnica da fermentação submersa em reatores biotecnológicos 
anaeróbicos. A utilização dos aditivos enzimáticos para estabilização, consegue alterar a matriz do solo depois da compactação, consequentemente perdendo a capacidade de reabsorção de água, não interferindo nos aspectos mecânicos depois que a água é reaplicada ao solo compactado (EUJINE et al., 2017c; SWETA; MAHESWAR, 2017).

Os aditivos enzimáticos aplicados como estabilizante, inicialmente são indicados para minimização de lama e poeira; demonstram resistências e impermeabilização dossolos, quando aplicadocomosub-base para o melhoramento técnico antes da pavimentação com asfalto, mineração, áreas agrícolas, áreas de controle à erosão, estradas de terra, estradas vicinais, ruas e rodovias, pátios de estacionamento, campos de aviação, áreas de proteção ecológica, parques, trilhas e caminhos, conserto e vedação de buracos em estradas de terra (GUTHRIE et al., 2015; SRAVAN; NAGARAJ, 2017).

As características das atividades enzimáticas do aditivo, assim como as categorias de obras e resultados com frequência resoluta, são entremeadas com ocorrências consequentemente desastrosas, desencadeando toda uma credibilidade perseverantemente adquirida. Apesar da ambiguidade, esse dilema instiga e impulsiona as pesquisas em universidades e centro de desenvolvimento especializados de norte a sul do Brasil. A despeito, mesmo que a técnica de estabilização de enzimas seja antiga, pode ser considerada ainda como em franco desenvolvimento (MALKO et al., 2015; CARMONA et al., 2017).

Especificamente os aditivos enzimáticos são para uso geotécnico, principalmente para construção rodoviária e para a confecção de blocos e tijolos; estão disponíveis para comércio num mercado mundial lucrativo e em franca e frequente expansão (GANAPATHY et al., 2017). Perfazendo, um screening na literatura e em sites especializados detecta-se menos de duas dezenas de compostos enzimáticos com atividade estabilizante de solo, estes produtos são patenteados por diferentes fabricantes, como descrito na Tabela 1, abaixo.

Tabela 1: Descrição das enzimas patenteada e seus fabricantes, respectivamente.

\begin{tabular}{cc}
\hline Produto & Fabricante/Representante \\
\hline Terrazyme & Nature Plus Inc. \\
EMC Squared & Soil Stabilization Products \\
Permazyme & Permazyme/Pacific/Globalzyme \\
Endurazyme & World Enzymes Austrália \\
Paczyme & Rainstorm \\
Earthzyme & Cypher International Ltda \\
RoadTech & Target Technologies Int. \\
UBIX & Enzymes Plus \\
ECOroads & TerraFusion \\
Nrzyma & AbiTechnology \\
Ecomax & ZymTec/i-Tec-India \\
EnzymeRoads & Eco Sustainable System
\end{tabular}




\begin{tabular}{cc} 
Roadzyme & Hobe Associates \\
PaveZyme & Omega Paving \\
EcoTerra & EcoTerra Technologies \\
PK-4 & Ecoenzymes Australia \\
Boroźyme & Boron Innovations \\
DZ-1X & Dhara Biotech \\
\hline
\end{tabular}

Fonte: Adaptação de BRAZETTI, R.; CASAGRANDE, M.D.T.; ALBUQUERQUE E SILVA, BH (2013)

Os aditivos enzimáticos são produtos comercializados praticamente no mundo todo e com bastante aceitação em locais como Austrália, África, Europa e os Estados Unidos principal produtor e exportador. Na América do Sul, praticamente todos os países da região fazem uso das bioenzimas como aditivos onde inclusive alguns já normatizaram seu uso, por exemplo, Chile, Peru e Equador (DHANESH, MOHANDAS, 2016; MUKESH et al., 2018).

No entanto, na América do Sul ainda não existe nenhuma indústria, somente produtos americanos, que vêm sendo importados e comercializados, como as bioenzimas TerraZyme da Nature plus Inc.; EMC Squared da Soil Stabilization Products Company Inc.; a Permazyme da Pacific Enzymes Inc., com aplicação para a iniciativa privada, alguns dos órgãos rodoviários estaduais e com mais frequência para os municipais (SAINI, VAISNAVA, 2015; BABY et al., 2016; SAHOO, SRIDEVI, 2018). No Brasil, a bioenzima da TerraZyme da Nature plus Inc. é a mais comercializada e aplicada em benefício da pavimentação. Entretanto, a empresa Enzyme Products, estuda as possibilidades de instalar sua fábrica brasileira para eliminar custos de importação (MALKO et al., 2015).

As pesquisas desenvolvidas por Malko et al. (2014), Saini (2015), Jadhav et al. (2016), Rafique et al. (2016), Eujine et al. (2017a) e Eujine et al. (2017b), corroboram a eficiência dos aditivos enzimáticos na estabilização de solo, todos os autores utilizaram em suas pesquisas o produto Terrazyme, solução constituída por enzimas extraídas da cana-de-açúcar. No entanto, as enzimas Urease foi empregado na pesquisa de Carmona et al. (2017) como agente estabilizante de solo, demonstrando resultados significativos e bem avaliados pelos pesquisadores.

Para Rafique et al. (2016), a proporção de dosagem 1/400 (aditivo/água), observou uma elevação nos valores de Índice Suporte Califórnia (ISC) sinalizou uma elevação de $55 \%$ da capacidade de suporte, demonstrando redução de custo de até $17 \%$ na construção de novas rodovias, e até $60 \%$ na manutenção das rodovias quando comparadas com rodovias sem estabilizadores de solo.

Nos diferentes estudos comparativos de substituição da cal por aditivos enzimáticos de estabilização de solos, proposto por Eujine et al. (2017a) e Eujine et al. (2017b), observaram elevação de três a seis vezes nos valores de ISC sob condições secas de um solo estabilizado com cal com adição da enzima e de solo estabilizado somente com a enzima, se comparado com o solo na condição natural. 
Para Santos et al. (2018) o uso do produto ESS-X, um aditivo a base de enzima, utilizado comercialmente no estado de Mato Grosso nas rodovias MT-486, resultou na resistência mecânica, exerceu a função esperada e elevou a RCNC do solo em estudo, principalmente na maior dosagem analisada, em que foi possível obter um solo com cerca de 3,6 vezes mais resistentes do que o solo puro.

\section{CONSIDERAÇÕES FINAIS}

A prospecção de novas tecnologias de estabilização química que proporcione melhoraria técnicas do solo do ponto de vista da engenharia civil, ainda é escasso no Brasil, visto que os aditivos químicos orgânicos, em especial as bioenzimas são substâncias empregadas como biocatalizadora de partículas de solos, formulada para aperfeiçoar as propriedades técnicas do solo, como: o aumentando a densidade, cimentação entre suas partículas e resistência à umidade, que resulta numa maior estabilidade e capacidade de massa para suportar maiores cargas.

A utilização desses aditivos enzimáticos acorre na engenharia rodoviária como um produto alternativo bastante interessante nas condições de economia e sustentabilidade, visto que são ecológicos e não agridem o meio ambiente. Portanto, conhecer o potencial desses aditivos ou propor novas metodologias de ensaio capaz de avaliar a influência desses agentes estabilizadores em todos as categorias de solos têm sido o maior desafio dos pesquisadores nas últimas décadas.

\section{REFERÊNCIAS}

AGARWAL, P.; KAUR, S. Effect of bio-enzyme stabilization on unconfined compressive strength of expansive soil. International Journal of Research in Engineering and Technology, v. 3, n. 5, p. 30-33, 2014.

BABY, M. et al. Experimental study of expansive soil stabilized with Terrazyme. Int. J. Eng. Res. Technol, v. 5, n. 1, p. 897-899, 2016.

CARMONA, J. P. et al. Biocimentação de um solo arenoso com recurso a enzimas: efeito de diversos fatores. Geotecnia, n.141 , p. 3-18, 2017. http://dx.doi.org/10.24849/j. geot.2017.141.01.

DHANESH, I. S.; MOHANDAS, T. V. Effect of bio-enzyme on geotechnical properties of Thonnakkal clay. Int. J. Eng. Trends Technol, v. 36, n. 9, p. 474-476, 2016.

DOS SANTOS, L. R. Estabilização de Solos com um Aditivo a Base de Enzimas para fins Rodoviários. E\&S Engineering and Science, v. 7, n. 3, p. 2-11, 2018. http://dx.doi. org/10.18607/ES201876930. 
EUJINE, G. N. et al. Accelerated Subgrade Stabilization Using Enzymatic Lime Technique. Journal of Material in Civil Engineering, v. 29, n.9, p. 5-12, 2017a. https:// doi.org/10.1061/(ASCE)MT.1943-5533.0001923.

EUJINE, G. N. et al. The engineering behavior of enzymatic lime stabilized soils. Ground Improvement, v. 170, n. 1, p. 1-1 1, 2017b. https://doi.org/10.1680/jgrim.16.00014.

EUJINE, G. N. et al. Influence of enzymatic lime on clay mineral behavior. Arabian Journal of Geosciences, v. 10, n. 20, p. 454, 2017c. https://doi.org/10.1007/s12517017-3238-z.

FIROOZI, A. A. et al. Fundamentals of soil stabilization. International Journal of GeoEngineering, v. 8, n. 1, p. 26, 2017. https://doi.org/10.1 186/s40703-017-0064-9.

GANAPATHY, G.P. et al. Bio-enzymatic stabilization of a soil having poor engineering properties. International Journal of Civil Engineering, v. 15, n. 3, p. 401-409, 2017. https://doi.org/10.1016/j.matpr.2018.06.329.

GUTHRIE, W. S. et al. Enzyme stabilization of low-volume gravel roads. Transportation Research Record: Journal of the Transportation Research Board, v. 2511, p. 112-120, 2015. https://doi.org/10.3141/2511-13.

MALKO, J. A. C. et al. Application of Enzymes for Stabilization of Soils in Paving. Key Engineering Materials, v. 668, p. 150-159, 2015. https://doi.org/10.4028/www.scientific. net/KEM.668.150.

MANU, A. S.; MAHENDRA, S. P. Strength Properties of Bioenzyme Treated Black Cotton Soil. International Journal of Applied Engineering Research, v. 13, n. 7, p. 302-306, 2018.

MUKESH, T. S. et al. Comparitive Analysis On Soil Properties By Adding Conventional Stabilizer With Enzymatic Stabilizer. International Journal of Advanced Science and Engineering Research, v. 3, n. 1, $30-36,2018$

RAFIQUE, U. et al. Application of bioenzymatic soil stabilization in comparison to macadam in the construction of transport infrastructure. Journal of Environmental Biology, v. 37, p. 1209-1215, 2016.

KUSHWAHA, S. S. et al. Stabilization of Red mud using eko soil enzyme for highway embankment. Materials Today: Proceedings, v. 5, n. 9, p. 20500-20512, 2018. https:// doi.org/10.1016/j.matpr.2018.06.427.

RAJORIA, V.; KAUR, S. A review on stabilization of soil using bio-enzyme. International Journal of Research in Engineering and Technology, v. 3, n. 1, p. 75-78, 2014. 
RAMAN, S. J. et al. Analysis on the strength charecteristics of clayey soil with geopolymer enzyme (biochemical enzyme). Rasayan J. Chem., v. 11, n. 4, p. 17291733, 2018. http://dx.doi.org/10.31788/RJC.2018.1143089.

SAHOO, S.; SRIDEVI, G. Soil stabilization using bio-enzyme. International Journal of Pure and Applied Mathematics, v. 118, n.24, p. 1- 10, 2018.

SAINI, V.; VAISNAVA, P. Soil estabilization by using Terrazyme. International Journal of Advances in Engineering \& Technology, v. 8, p. 566-573, 2015.

SHAKA, Priyanka M.; SHAKA, Surekha M. Laboratory investigation on Black cotton soils and Red soil stabilized using Enzyme. Int. Res. J. Eng. Technol, v. 3, n. 6, p. 325-330, 2016.

SODHI, P. S.; OCEAN, Y. K. Stabilization of soil using alkaline bio-enzyme (Alkazyme). International Research Journal of Engineering and Technology, v. 05 n. 8, p. 16811685, 2018. https://doi.org/10.15680/IJIRSET.2018.0708043.

SRAVAN, M. V.; NAGARAJ, H. B. Potential Use of Enzymes in the Preparation of Compressed Stabilized Earth Blocks. Journal of Materials in Civil Engineering, $\mathrm{V}$. 29, n. 9, p. 04017103, 2017.

SWETA D.; MAHESWAR M. An Investigation on "Behaviour of Bio Enzyme Stabilized Expansive Soil. International Journal of Recent Scientific Research, v. 8, n. 8, p. 19029-19034, 2017. http://dx.doi.org/10.24327/ijrsr.2017.0808.0615.

THOMAS, Ansu; TRIPATHI, R. K.; YADU, L. K. A Laboratory Investigation of Soil Stabilization Using Enzyme and Alkali-Activated Ground Granulated BlastFurnace Slag. Arabian Journal for Science and Engineering, v. 43, n. 10, p. 5193-5202, 2018. https://doi.org/10.1007/s13369-017-3033-x.

VARUNKUMAR, G. et al. Stabilization of Black Cotton Soil using Terrazyme. International Journal of Engineering Science, v. 8, n. 5, p. 17761, 2018.

Recebido em: 16/05/2019.

Aceito em: 26/06/2019. 